\title{
A Poluição do Mar e o Instituto Hidrográfico
}

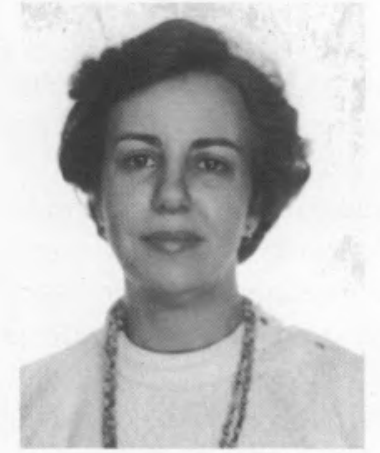

M. Manuela Cruces

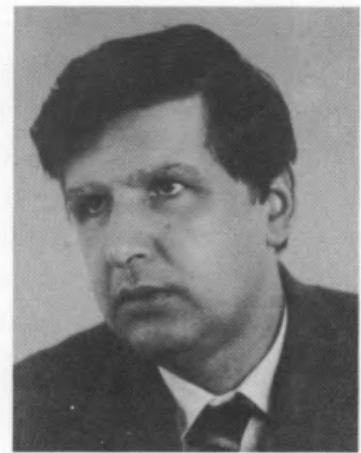

José Luís Biscaya
Licenciada em Engenharia Química Industrial pelo Instituto Superior Técnico em 1970.

Ingressou no Instituto Hidrográfico em 1971 onde tem desenvolvido trabalhos no âmbito de oceanografia química e da poluição, desempenhando actualmente o cargo de Chefe da Divisão de Química e Poluição.
Durante muito tempo julgou-se que o Mar tinha uma capacidade ilimitada de fornecer recursos e de absorver os desperdícios da actividade humana. Este conceito levou a cometer uma série de erros que só demasiado tarde se tornaram visíveis.

A pesca excessiva, a captura desenfreada de mamíferos marinhos e a poluição nas suas várias formas, têm contribuído para degradar o Meio Marinho e alterar equilíbrios ecológicos.

\section{Sinais de Alarme}

A protecção do ambiente marinho é dificultada pelo desconhecimento do efeito da maioria das substâncias nele lançadas e dado que as alterações ecológicas não são imediatas nem sempre se tem a percepção da verdadeira causa.

Talvez a tragédia de Minamata possa ser apontada como o despertar da Humanidade para os problemas da poluição do mar. O aparecimento e disseminação de uma nova e estranha
Licenciado em Ciências Físico-Químicas pela Faculdade de Ciências de Lisboa (1965) e especializado em Química Têxtil pela Faculdade de Ciências de Coimbra.

Iniciou os seus trabalhos de Oceanografia em 1968 ao prestar serviço militar no Instituto Hidrográfico em cujo quadro de pessoal civil veio a ingressar em 1971.

Actualmente é responsável pelo núcleo de Hidrocarbonetos da Divisão de Química e Poluição.

doença nessa comunidade piscatória, entre 1956 e 1960, só mais tarde foi relacionada com os elevados teores de mercúrio acumulado pelos peixes, principal alimento dos seus habitantes; no entanto, desde 1930 que eram lançados, na Baía de Minamata (Japão), resíduos de mercúrio, provenientes de uma fábrica de formaldeído e cloreto de vinilo que usava óxido mercúrico como catalisador.

Factores biológicos como a bioacumulação e factores físicos como as correntes, fazem com que a poluição originada nos Continentes não se dissemine no imenso volume do Oceano e se acumule preferencialmente na faixa litoral, que é também a zona mais rica em recursos vivos.

${ }^{3}$ Instituto Hidrográfico, Lisboa. 


\section{Efeitos da Poluição}

O Homem apercebe-se da existência da poluição pelos seus efeitos inestéticos, pelo desaparecimento de certas espécies e pelos efeitos patológicos que ele próprio sofre.

Os efeitos inestéticos, por serem os mais evidentes e imediatos, são normalmente os que acarretam menor perigo, uma vez que se podem minimizar, dado o conhecimento, à partida, da causa a combater; é o caso, por exemplo das manchas de hidrocarbonetos.

Os efeitos ecológicos que resultam na quebra da cadeia trófica ou na substituição de algumas espécies por outras mais resistentes, são menos visíveis e algo enganadores. Um observador menos avisado pode considerar florescente uma zona só povoada por peixe ultra-resistente, sem valor económico e certamente com elevados teores de poluentes acumulados. A acção directa sobre a saúde humana é mais difícil de relacionar com a poluição do mar. $\mathrm{O}$ Homem tem normalmente uma alimentação muito variada, o que pode contribuir em dada medida para o proteger, não evitando, no entanto, efeitos imediatos e determinantes no caso do consumo de bivalves ou peixes contaminados por bactérias ou vírus.

\section{Principais Poluentes}

Embora seja impraticável fazer uma lista exaustiva dos poluentes susceptíveis de atingir o Meio Marinho, podem sistematizar-se em cinco grupos: metais, produtos químicos orgânicos sintéticos, hidrocarbonetos, radionuclídeos e resíduos sólidos. Há ainda a acrescentar as substâncias redutoras que geram zonas anóxicas e os microorganismos (vírus, bactérias, etc.) que provocam doenças.

Quase todos os metais são bioacumuláveis em um ou mais componentes da cadeia trófica. Embora alguns, como o ferro e o zindo, sejam essenciais ao desenvolvimento dos organismos marinhos, outros, como o mercúrio, o cádmio, o cobre e o arsénio, são marcadamente tóxicos. Sabe-se que alguns organismos acumulam preferencialmente determinados metais, mas desconhece-se tanto o mecanismo, como a causa de tal bioacumulação. Existem estudos de toxicidade, efectuados em laboratório, mas de uma maneira geral não reproduzem eficazmente o meio ambiente natural.

Anualmente são sintetizados dezenas de milhar de novos produtos químicos orgânicos, dos quais pelo menos mil são lançados no mercado internacional. Duma maneira geral, o efeito destes produtos sobre o ambiente não é estudado antecipadamente e, portanto, nada impede que ao fim de alguns anos se constate que muitos deles são perigosos e não biodegradáveis. Os compostos organoclorados têm sido objecto de estudo, no que se refere aos efeitos provocados no ambiente, devido em grande parte aos danos ecológicos causados pelo emprego do DDT, que ainda hoje, passados tantos anos sobre a proibição do seu uso se encontra como contaminante em organismos marinhos mesmo em zonas longe de qualquer possível descarga destes produtos, o que prova a sua grande difusão no Meio Marinho. Os organofosforados e os organoestanosos, também bioacumuláveis, fazem parte das preocupações actuais, devido à sua crescente utilização.

Os hidrocarbonetos constituem um caso muito importante, porque, para além da sua grande utilização e consequente descarga de resíduos nos efluentes, há a considerar o seu transporte por navios. Calcula-se que, incluindo os casos de naufrágio, anualmente atingem o Oceano cerca de seis milhôes de toneladas de hidrocarbonetos cujo efeito nos recursos vivos é diverso; provocam, por exemplo, a morte de aves marinhas, que ficam com as penas cobertas de petróleo, a destruição de bancos de moluscos e a morte de peixes por colmatação das brânqueas, para além de alterarem a função fotossintética do fitoplancton por impossibilidade de a luz solar atravessar a camada que se forma à superfície da água do mar; alguns produtos refinados são mesmo especialmente tóxicos. Quando atingem praias ou outras zonas de lazer, há também que ter em conta o seu efeito inestético. Embora os danos provocados por grandes derrames de hidrocarbonetos levem muito tempo a reparar, não se julga que o efeito sobre o ecossistema seja permanente. No entanto em zonas muito frias, como por exemplo o Ártico, a regeneração é mais lenta e os efeitos mais persistentes.

$\mathrm{O}$ problema da radioactividade tem vindo a ser objecto de atenção mundial, devido às graves consequências que acarreta. As centrais nucleares têm sistemas de segurança cada vez mais sofisticados, o que não impede que surjam acidentes, como o recente caso de Chernobyl, que atingiu uma área considerável. No que respeita aos resíduos radioactivos, existe legislação que regulamenta a sua imersão no Oceano em zonas determinadas e em condições específicas; no entanto, podem ocorrer fugas, apesar de serem tomadas todas as medidas de segurança; além disso, é sabido que se têm verificado descargas de resíduos radioactivos no Meio Marinho fora das zonas autorizadas e não obedecendo às regras de segurança estabelecidas. Há ainda a acrescentar o perigo respeitante ao trânsito de sumarinos nucleares, nos Oceanos, com possibilidade de acidentes, como o que ocorreu há bem pouco tempo no Mar da Noruega, cujas consequências ainda não foram bem avaliadas.

Os resíduos sólidos que atingem o Oceano ascendem a vários milhões de toneladas por ano e têm as mais variadas origens e composição. Estes produtos causam problemas à navegação e muitas vezes provocam a morte de mamíferos marinhos enredando-os ou sufocando-os; a descarga de resíduos hospitalares (seringas, pensos, invólucros com restos de sangue, etc.), que devido ao regime de ventos e correntes podem ser arrastados para a costa, já conduziu ao encerramento de diversas praias.

Os efluentes com elevado poder redutor ou grande quantidade de matéria em suspensão, como é o caso dos provenientes da maioria das fábricas de celulose, têm efeito nocivo para a vida no meio receptor, além de o tornarem desagradável pelo cheiro que exalam.

\section{Entrada de Poluentes no Oceano}

O Homem é o responsável pela poluição do Oceano. Os efluentes domésticos e industriais, mesmo quando tratados, contêm uma carga poluente que atinge o Oceano, directamente ou via rios; os contaminantes lançados na atmosfera pela indústria, ao serem arrastados pela chuva, entram no ciclo da água e a lixiviação dos Continentes arrasta os produtos usados na agricultura quer directamente para o mar, quer para os rios, que os transportam para o mar. É também de considerar a imersão e incineração, deliberada ou acidental, de cargas transportadas por navios. 


\section{Controlo da Poluição do Mar}

Constatada a existência da poluição nos mares, preço que a Humanidade paga pelo seu desenvolvimento, impõe-se a consciencialização dos perigos que daí advêm e a tomada de medidas que protejam o Meio Marinho desta contínua agressão.

A diminuição da carga poluente que atinge o Oceano, passa pela substituição das tecnologias actuais por tecnologias limpas, pelo tratamento mais eficaz dos efluentes domésti$\cos$, industriais e agrícolas, pela limitação da imersão e incineração de substâncias no mar e até pela substituição do fabrico de determinados produtos, por outros considerados menos perigosos.

A Comunidade Internacional, sensibilizada para estes problemas, estabeleceu diversas Convenções e Tratados com a finalidade de controlar e minimizar, em zonas específicas, a poluição existente e de regulamentar ou mesmo proibir actos considerados nocivos para o Meio Marinho.

A Zona Económica Exclusiva Portuguesa é abrangida por várias Convenções Internacionais. Entre estas Portugal ratificou a Convenção para a Prevenção da Poluição Marinha Causada por Operações de Imersão de Detritos e Outros Produtos (Convenção de Londres), a Convenção para a Prevenção da Poluição Marítima causada por Operações de Imersão efectuadas por Navios e Aeronaves (Convenção de Oslo) e a Convenção para a Prevenção da Poluição Marinha de Origem Telúrica (Convenção de Paris). A primeira destas Convenções aplica-se a todo o Mundo, enquanto que as duas últimas se aplicam a parte dos Oceanos Atlântico e Árctico. As Convenções de Oslo e Paris, além de terem o seu próprio Grupo de Trabalho Consultivo, criaram um Grupo Conjunto de Monitorização, que avalia os Programas Nacionais e propõe um Programa Conjunto, com a finalidade de efectuar a vigilância, o controlo e o efeito de determinados parâmetros em áreas seleccionadas, nos diferentes compartimentos do Meio Marinho. As áreas em estudo em Portugal são os Estuários dos Rios Lima, Tejo e Sado e as Rias de Aveiro e Faro, competindo ao Instituto Hidrográfico tudo o que respeita a análises de água e sedimento e ao Instituto Nacional de Investigação das Pescas, as análises de seres vivos.

Paralelamente a este Grupo Conjunto e dependendo dos Grupos Consultivos de cada Convenção, existem outros Grupos de Trabalho, como por exemplo, o Grupo dos Sectores Industriais, o Grupo de Avaliação do Cumprimento das Normas de Qualidade do Ambiente, o Grupo de Entradas Atmosféricas de Poluentes para as Águas da Convenção, o Grupo dos Nutrientes, o Grupo de Poluição por Hidrocarbonetos, o Grupo de Entrada de Poluentes via Rios, etc., que analisam o estado de desenvolvimento e cumprimento das Normas estabelecidas pelas Convenções.

Além do Programa Conjunto de Monitorização, já referido, os Países, que são Partes Contratantes das Convenções, têm outras obrigações que, em Portugal, não são todas cometidas ao mesmo Organismo:

- os dados qualitativos e quantitativos dos efluentes das indústrias são obtidos pela Secretaria de Estado do Ambiente e Recursos Naturais e pela Secretaria de Estado da Indústria e Energia;

- os dados de cádmio e mercúrio em organismos vivos, para provar o cumprimento das Normas de Qualidade do Ambiente, são fornecidos pelo Instituto Nacional de Invesntigação das Pescas;

- os dados referentes a poluentes atmosféricos são cedidos pela Secretaria de Estado do Ambiente e Recursos Naturais; - os dados de nutrientes e de hidrocarbonetos são fornecidos pelo Instituto Hidrográfico;

- a caracterização química de todo o material dragado é efectuada no Instituto Hidrográfico.

Também no âmbito das Convenções tiveram início em 1988 no Instituto Hidrográfico estudos sobre entradas de poluentes pelos rios (Vouga), ou pelos efluentes (Estuário do Sado), bem como sobre ciclos biogeoquímicos (Ria Formosa).

Como já foi referido, as Convenções pretendem também regulamentar actos considerados de poluição. Nesse sentido existem já algumas decisões relacionadas com a diminuição de descargas de poluentes e sua eliminação a médio prazo. Está por exemplo, prevista a eliminação do mercúrio nas pilhas alcalinas de manganês e nos produtos destinados à agricultura, bem como a substituição dos termómetros de mercúrio por outros digitais. Em relação ao cádmio, prevê-se a sua substituição nas pilhas e eliminação nos adubos fosfatados. Quanto aos PCB's, está em estudo a cessação da sua utilização em transformadores e em condensadores a partir de 1995. Para fazer cumprir as regras estabelecidas prevê-se inclusivamente regulamentar um sistema de tarifação.

No âmbito da poluição do mar, o Instituto Hidrográfico desenvolve outras actividades, para além das já mencionadas:

- procede à monitorização de hidrocarbonetos na zona atlântica adjacente ao território nacional, a qual está sujeita a um considerável tráfego de petroleiros;

- efectua, nos casos de derrames de hidrocarbonetos, análises de comparação do produto colhido no mar com produtos colhidos nos vários navios suspeitos e elabora o parecer sobre a identificação do presumível poluidor;

- efectua estudos de impacte ambiental, nomeadamente no caso de prospecção petrolífera, de instalação de Centrais Térmicas e de descarga ou imersão, acidental ou voluntária, de produtos perigosos no Meio Marinho;

- elabora pareceres sobre pedidos de licenciamento de marinas, emissários submarinos e instalação de indústrias na orla costeira.

Para cumprir a sua missão que envolve tão variadas solicitações, o Instituto Hidrográfico tem equipado os seus laboratórios com o mais moderno equipamento e conseguiu formar uma equipa de investigadores e técnicos especialmente vocacionados para estes assuntos. A excelente qualidade analítica do seu trabalho tem sido comprovada por diversas intercalibrações internacionais em que tem participado.

\section{Referências}

-Waldichuk, M., «La contaminación mundial del mar: una recapitulación». Comission Oceanográfica Intergubernamental, Colección Técnica 18. Unesco 1977.

- Sousa, N., "Poluição do Mar» Anais do Clube Militar Naval, Vol. CXII, 1982, pág. 969-1015.

- $\propto$ A Framework for the Implementation of the Comprehensive Plan for the Global Investigation of Pollution in the Marine Environment». Intergovernmental Oceanographic Comission, Technical Series 25, Unesco 1984. 


\section{Convite à Reflexão}

\section{O Homem e o Ambiente}

As transformações produzidas no nosso meio pelas aplicações da ciência exercem sobre nós efeitos acentuados. Estes efeitos têm um carácter inesperado. São muito diferentes dos esperados e que seriam legítimos dadas as melhorias de toda a ordem introduzidas no habitat, no modo de vida, na alimentação, na educação e na atmosfera intelectual dos seres humanos. Como se obteve um resultado tão paradoxal?

Poderíamos dar uma resposta simples a este problema. A civilização moderna encontra-se em má posição porque não nos convém. Foi construída sem conhecimento da nossa verdadeira natureza. Deve-se ao capricho das descobertas científicas, do apetite dos homens, das suas ilusões, das suas teorias e dos seus desejos. Apesar de ter sido edificada por nós, não foi feita à nossa medida.

Na verdade, é evidente que a ciência não seguiu nenhum plano. Desenvolveu-se ao acaso, com o nascimento de alguns homens de génio, a forma do seu espírito e o caminho que tomou a sua curiosidade. Não se inspirou de modo nenhum no desejo de melhorar o estado dos seres humanos. As descobertas produziram-se ao sabor da intuição dos cientistas e das circunstâncias mais ou menos fortuitas das suas carreiras. Se Galileu, Newton ou Lavoisier tivessem aplicado os poderes do seu espírito ao estudo do corpo e da consciência, talvez o nosso mundo fosse diferente do que é hoje. Os cientistas ignoram para onde vão. São guiados pelo acaso, por racioncínios subtis, por uma espécie de clarividência. Cada um deles é um mundo à parte, governado pelas suas próprias leis. De tempos a tempos, certas coisas, obscuras para os outros, tornam-se claras para eles. Em geral, as descobertas são feitas sem nenhuma revisão das consequências. Mas a forma da nossa civilização resultou destas consequências.

Entre as riquezas das descobertas científicas, fizemos uma escolha. E esta escolha não foi de modo nenhum determinada pela consideração de um interesse superior da humanidade. Limitou-se a seguir as nossas tendências naturais. Dos princípios da maior comodidade e do menor esforço, do prazer que nos proporcionam a velocidade, a mudança e o conforto, e também da necessidade de escaparmos a nós mesmos resultou o sucesso das novas invenções. Mas ninguém perguntou como suportariam os seres vivos a aceleração enorme do ritmo de vida.

(...) Na organização do trabalho industrial, a influência da fábrica no estado fisiológico e mental dos operários foi completamente desprezada. A indústria moderna baseiase na concepção da máxima produção ao mais baixo preço a fim de que um indivíduo ou um grupo de indivíduos ganhem o máximo de dinheiro possível. Desenvolveu-se sem nenhuma ideia da verdadeira natureza dos seres humanos que conduzem as máquinas e sem a preocupação quanto ao que produz sobre eles e sobre a sua descendência a vida artificial imposta pela fábrica. A construção das grandes cidades fez-se sem respeito por nós. A forma e as dimensões dos edifícios modernos inspiraram-se na necessidade de obter o máximo rendimento por metro quadrado de terreno e de oferecer aos locatários gabinetes e apartamentos agradáveis. Conseguiu-se, assim, construir casas gigantes que acumulam num espaço restrito massas muito mais consideráveis de indivíduos. Estes vivem com prazer, usufruindo de conforto e de luxo, não se apercebendo de que estão privados do necessário. A cidade moderna é composta por habitações monstruosas e ruas obscuras cujo ar é poluído pelo fumo, o pó, os vapores da gasolina e os produtos da sua combustão, rasgadas pelo ruído dos camiões e dos carros eléctricos e permanentemente repletas de multidões. É evidente que esta cidade não foi construída para bem dos seus habitantes.

(...) O homem deveria ser a medida de tudo. De facto, ele é um estranho no mundo que criou. Não soube organizar este mundo para ele, porque não possuía um conhecimento positivo da sua própria natureza. O enorme avanço das ciências das coisas inanimadas em relação às dos seres vivos é, portanto, um dos acontecimentos mais trágicos da história da humanidade. O meio construído pela nossa inteligência e pelas nossas intenções não se ajusta às nossas dimensões nem à nossa forma. Não nos serve. Sentimo-nos infelizes. Degeneramos moralmente e mentalmente. São precisamente os grupos e as nações em que a civilização industrial atingiu $o$ apogeu que mais enfraquecem. Neles, o retorno à barbárie é mais rápido. Permanecem sem defesa perante o meio adverso que a ciência lhes forneceu. Na verdade, a nossa civilização, tal como as que a antecederam, criou condições em que, por razões que não conhecemos exactamente, a própria vida se torna impossível. A inquietação e a infelicidade dos habitantes da nova cidade têm origem nas instituições políticas, económicas e sociais, mas sobretudo na sua própria degradação. São vítimas do atraso das ciências da vida em relação às da matéria.

Só um conhecimento muito mais profundo de nós mesmos pode remediar este mal. Graças a ele, veremos por que mecanismos a existência moderna afecta a nossa consciência e o nosso corpo. Aprenderemos como adaptar-nos a este meio, como defender-nos dele e também como substituí-lo no caso de se tornar indispensável uma revolução. Ao mostrar-nos o que somos, as nossas potencialidades e a maneira de as actualizar, este conhecimento fornecer-nos-á uma explicação para o nosso enfraquecimento fisiológico, para as nossas doenças morais e intelectuais. Só ele nos pode desvendar as leis inexoráveis em que estão encerradas as nossas actividades orgânicas e espirituais, estabelecer a distinção entre o interdito e o permitido, ensinar-nos que não somos livres de modificar, segundo a nossa fantasia, o nosso meio e nós mesmos. Na verdade, desde que as condições naturais da existência foram suprimidas pela civilização moderna, a ciência do homem tornou-se a mais necessária de todas as ciências.

Alexis Carrel, «O Homem Esse Desconhecido» 